\title{
Importance of Breast Self-Examination among Rural Women for Early Detection of Breast Cancer: Bangladesh Perspectives
}

\author{
Negar Fouzia ${ }^{1}$
}

Breast cancer is one of the most common cancers among females worldwide. Global statistics show the annual incidence of breast cancer is increasing and this is occurring more rapidly in countries with a low incidence rate of breast cancer (Parkin et al., 2005). Although breast cancer usually develops after the age of 45 , the age of onset is decreasing and more young women than ever are affected (Fry and Prentice-Dunn 2006). Young women's cancers are generally more aggressive and result in lower survival rates, making early detection even more important (Ludwick and Tanya 2001). Promotion of self-care, an attitude fostered early in life may pay lifelong dividends. The adolescent period is a time of rapid change that provides teaching opportunities for shaping health behaviors into adulthood. For example, teaching breast self-care may encourage positive behaviors such as performing breast self-examination (BSE) and seeking regular professional breast examinations.

Breast cancer is the most common female cancer worldwide representing nearly a quarter (23\%) of all cancers in women. The global burden of breast cancer is expected to cross 2 million by the year 2030, with growing proportions from developing countries (Madanat and Merrill 2002). Globally, cancer is one of the top ten leading causes of death and it is estimated that 7.4 million people died of cancer in 2004 and, if current trends continue, 83.2 million more will have died by 2015; however, Among women, breast cancer is the most common cause of cancer mortality, accounting for $16 \%$ of cancer deaths in adult women (Porter 2008).

Health behaviors such as BSE can help empower women to take some control and responsibility over their health promotion. For younger women, BSE education and adherence are a gateway to health promotion behaviors which set the stage for adherence to clinical breast examination and mammography screening later in life. Although the value of BSE is controversial (McCready et al., 2005), American Cancer Society recommends as an option breast awareness and BSE for early detection of breast cancer. It benefits women in two ways: women become familiar with both the appearance and the feel of their breasts and detect any changes in their breasts as early as possible. BSE makes women more "breast aware", which in turn may lead to an earlier diagnosis of breast cancer. The rationale behind extending BSE practice as a screening test is the fact that breast cancer is frequently detected by women themselves without any other symptoms ${ }^{11}$.

Breast cancer is a major life-threatening public health problem of great concern (Soyer et al., 2007). If rural women's knowledge towards breast cancer and its screening is remarkable, it lets health policy makers strengthen the trend being taken, but if the reverse occurs the finding will serve as a source for health policy planners to design strategy that can reshape and fill the gap. In addition the result will have direct implication to the growth of nursing profession towards early detection and prevention of complication. Furthermore to appreciate the nurse's stand to this world warning issue and to equip them based on the identified gaps as to that they can be able to manage problems of the community they serve. Several studies have reported that breast cancer is the most common cancer and principal cause of cancer deaths in women and is therefore a world concern (Dündar et al., 2006; McCready et al., 2005). Education about the importance of early detection in decreasing mortality rates might be of value in raising awareness of the various methods of early detection of breast cancer. More research is also needed to identify the underlying variables that might influence nurses' own practice of early detection methods of breast cancer. Empowering nurses with information about early detection methods and their related benefits could help in advancing their skills in performing breast self-examination and expanding their role as client educators.

${ }^{1}$ Dr. Negar Fouzia, Thesis Part Student, Department of Public Health, North South University, Dhaka, Bangladesh; Email: negarfouzia@gmail.com; Cell no.: +8801712101747 
As breast cancer is a topic that is not freely discussed in Bangladesh because of cultural taboo, there is an urgent need for information and education on awareness of breast cancer and its early detection measures (Ertem and Kocer, 2009). Promotion of self-care, an attitude fostered early in life, may pay lifelong dividends. The adolescent period is a time of rapid change that provides teaching opportunities for shaping health behaviors into adulthood. For example, teaching breast self-care may encourage positive behaviors such as performing breast self-examination (BSE) and seeking regular professional breast examination. Health behaviors such as BSE can help empower women to take some control and responsibility over their health promotion. For younger women, BSE education and adherence are a gateway to health promotion behaviors which set the stage for adherence to clinical breast examination and mammography screening later in life.

[How to cite this article: Fouzia N. Importance of Breast Self-Examination among Rural Women for Early Detection of Breast Cancer: Bangladesh Perspectives. Journal of Science Foundation 2017;15(2):29-30]

[Journal of Science Foundation 2017;15(2):29-30]

\section{References}

Dündar PE, Özmen D, Öztürk B, Haspolat G, Akyıldız F, Çoban S, Çakıroğlu G. The knowledge and attitudes of breast selfexamination and mammography in a group of women in a rural area in western Turkey. BMC cancer. 2006;6(1):43

Ertem G, Kocer A. Breast self-examination among nurses and midwives in Odemis health district in Turkey. Indian journal of cancer. 2009;46(3):208

Fry RB, Prentice-Dunn S. Effects of a psychosocial intervention on breast self-examination attitudes and behaviors. Health education research 2006;21(2):287-95

Ludwick R, Tanya G. Breast Self-exams by Teenagers: Outcome of a Teaching Program. Cancer Nursing 2001;24(4): 315-319

Madanat H, Merrill RM. Breast cancer risk-factor and screening awareness among women nurses and teachers in Amman, Jordan. Cancer Nursing 2002;25(4):276-282

McCready T, Littlewood D, Jenkinson J. Breast self-examination and breast awareness: a literature review. Journal of Clinical Nursing. 2005;14(5):570-8

McCready T, Littlewood D, Jenkinson J. Breast self-examination and breast awareness: a literature review. Journal of Clinical Nursing. 2005;14(5):570-8

Parkin DM, Bray F, Ferlay J, Pisani P. Global cancer statistics, 2002. CA: a cancer journal for clinicians. 2005;55(2):74-108

Porter P. Westernizing" women's risks? Breast cancer in lower-income countries. New England Journal of Medicine 2008;358(3):213-216

Soyer MT, Ciceklioglu M, Ceber E. Breast cancer awareness and practice of breast self-examination among primary health care nurses: influencing factors and effects of an in-service education. Journal of Clinical Nursing. 2007;16(4):707-15 